\title{
Humanism and the Great Opportunity of Intelligent User Interfaces for Cultural Heritage
}

\author{
Oliviero Stock
}

\begin{abstract}
In the spirit of the modern meaning of the word humanism, if technology aims at the flourishing of humans, it is of the greatest value to empower each human being with the capability of appreciating culture, in an inclusive, individual-adaptive manner. In particular, in this brief chapter, the case is made for the opportunity that intelligent user interfaces can offer specifically in the area of culture, beyond the obvious infrastructural advantages we are all familiar with. Insight is provided on research aimed at the continuous personal enriching of individuals at cultural sites, approaching the ancient humanistic vision of connecting us to our cultural past, now made possible for all, not just for an elite.
\end{abstract}

Humanism puts humans at the center of interest for all aspects of life, on a philosophical as well as on practical terms. Its roots are in Cicero's term humanitas, which in substance meant the development of all forms of human virtue and became an important movement in Italy in the fourteenth century, including outstanding figures of culture and art, such as the poet Francesco Petrarca, before spreading to other areas in Europe. Humanism emphasized the connection to classical culture and, in a way, offered to overcome limits of time. It was not only passive tribute to ancient culture, but active connection: authors like Petrarca gave meaning to the concept of cultural heritage and went all the way to even write letters directly to classical authors.

I really believe we are now at a historical point, one that can steer the human relation to cultural heritage and other cultural aspects in the spirit of a modern, digital humanism. If technology aims at the flourishing of humans, it is of the greatest value to empower each human being with the capability of appreciating culture, in an inclusive, individual-adaptive manner. In particular, in this brief chapter, I would like to make the case for the opportunity that intelligent user interfaces can offer

\footnotetext{
O. Stock $(\bowtie)$

Fondazione Bruno Kessler, Trento, Italy

e-mail: stock@fbk.eu 
specifically in the area of culture, beyond the obvious infrastructural advantages we are all familiar with.

In general, we can say that IT and the Web, though they have offered enormous opportunities for human cultural enrichment, have not met the expectations that many had. Most of us believed that technology would have brought same rights for all, opportunities to advance the cultural level, natural exposition to different points of view, in sum a cultural improvement in our society. It has happened to a very limited extent.

At the same time, undesired effects have been widespread; the digital world has brought with it a strong danger of pseudo-cultures that hide aggressive intents and, on the other hand, of cultural uniformity, not to say cultural imperialism. Often, eventually technology has been used for spreading deplorable contents and has even been the tool of choice for hate messages, without us doing much to prevent it. Only recently, a defensive technological effort has started to counter hate speech, and, just to mention a popular theme, fake news are still not easy to detect and counter automatically nor semi-automatically. So there are many challenges ahead on the digital defense side, on the intersection of culture and ethics.

In any way, as I said, here I would like to discuss the great positive potential of intelligent technologies for cultural heritage. Cultural heritage has many forms; some forms are meant to be immaterial and reproducible from the beginning, like for instance texts, music, or films and, basically, theater. Intelligent technologies may help accessing and interpreting the material. A good example is natural language processing techniques for automatically finding influence relations in concept formation among different authors (see Van Camp and Van den Bosch 2012) or in determining (causal) chains in historical events. Yet, here I would like to focus on physical cultural heritage, on the incomparable experience of being in front of the original material artifact, being it at museums, at historical or art-relevant sites, or possibly also at other unstructured "every day" locations. For a museum, there are three main aspects for digital intervention: preservation, organization, and appreciation. Artifact preservation by means of technologies has a long history and is improving steadily, but it is not the focus of this chapter. Organization is the classical work of the curator, who may involve architects for getting the best out of the combination of exhibits and available space. In modern museums, technology may help for all aspects of design and basic offer to the public, for security in the museum, and also for real-time sensing of visitors' behavior in order to improve the availability of resources for the visitors.

The really novel prospect - and the one addressing the core of humanism - comes from intelligent interfaces for cultural heritage appreciation by the visitor. In abstract, we can think of three phases: before the cultural visit, during the visit, and after the visit. The "before the visit" phase, obtaining information and getting prepared for making the most out of the coming visit, has already a variety of tools available. In addition, in the future, we shall enjoy continuity, so that the actual visit exploits what was explored earlier at home, including a model of the visitor (see Ardissono et al. 2012), acquired beforehand. 
In fact, when it comes to the actual visit, the key element is that nothing should take the place of the emotional experience of being in front of the original artifact. The computer interface to culture, and in general any interface, must not pose limits to a natural experience but should augment it. In addition, the computer-based intervention should connect the current experience to a learning model. We want the interface to take into account the cognitive, the emotional, and the physical state of the visitor (where he/she is, tiredness, etc.), to be guided by his/her own motivation, tastes, and preferences, in case, to negotiate what should not be missed, but not to impose a rigid agenda. This flexibility and user adaptation require the visitor model, which must be as accurate as possible, to be continuously updated in the course of the visit. Presentation strategies then depend on media and modalities available, but again should take into account movement in space, and what was explored previously, so that the presentation, which necessarily is language-based, is appropriately personalized and can refer to what drew the visitor's attention previously (Kuflik et al. 2011). Various techniques have been studied, based on hearing, combination with reading, combination with seeing images, all the way to dynamic documentaries with a multimedia narration produced automatically for the current situation (Stock et al. 2007). It is also only natural in this context to be able to provide cultural information from different points of view. Cultural descriptions may be controversial, and criticism and diverse viewpoints add to our understanding. On the visual side, various forms of augmentation of what is being perceived have been proposed, for instance, reconstruction of a building superimposed on the view of the existing fragment (Aliprantis and Caridakis 2019).

People tend to visit museums and historical sites in small groups, family, or friends. Etnographers have shown that conversation is a fundamental factor in the success of the cultural experience. Sharing the emotion, discussing, criticizing, enlarging the perspective help going deeper, learning, and developing a taste for the cultural experience. Also for this aspect, intelligent interfaces can help. Just to mention one example: while theater in the museum had been proposed for some time, inspired by a mobile theater tradition that we can date to the Middle Ages, an original smartphone-based drama technology for the museum was recently created and initially experimented with. The intelligent technology-based drama system gives an active role to visitors and subtly induces conversation about the exhibit contents among the group members, while they move along in their visit (Callaway et al. 2012). This approach is based on dynamically adapted scenes and requires as enabling technology, in addition to accurate positioning, also proximity and group behavior detection. It involves distance communication, and it can be exploited for allowing participation to the visit by elderly or handicapped members of the small group, who cannot leave home.

Another aspect that technology consents is some form of interaction across time: for instance, leaving traces of a visit, in the form of spoken comments that could be heard by your grandchildren when they will happen to be just at the site you are visiting now. Or, more sophisticated: entertaining a dialog with someone not there anymore, through interpretation of visitor's utterances by a dialog management 
system and clever understanding and composing interview fragments of the departed one (Artstein et al. 2014).

The "after the visit" setting is important for group sharing and reflecting about the visit and consolidating the group experience. At this point, it is obvious that intelligent technology, having a record of the users' competence and current experience, of what each one has seen, what drew his/her attention, etc., can help the conversation, help reinforcing the memory, and provide new stimuli for the individual and for specific insights.

So much for the visit to the museum, or to the art site, as the focus point of "material" culture. A challenge for the future is also to connect all cultural experiences. The idea is in the first place that a system that accompanies you to a visit knows about your previous visits to the present museum or to other ones, about what attracted you; it may have a model of how much you may recall and what the novel knowledge should be integrated to. More ambitious is the idea of ubiquitous cultural experience: in all circumstances, the fact that you are nearing a certain site may lead a proactive system to negotiate with your individual model, so to promote some local cultural aspects related to your interests, and find the best way to get your attention and the time for exploring the site and having a personalized presentation (Kuflik et al. 2015). In this spirit, for instance, sites of historical events can be connected to what was learned in a museum, or history narration can be expressed not only in relation to locations of big events but also for "bottom-up" history. To complete this picture, it could be up to local residents, and especially for school projects, to design contents to value their territory.

Having spoken of the opportunity for cultural heritage appreciation, I would like to mention a different, but socially important, theme, still related to cultures, in this case mostly meaning ethnical aspects. I refer to the proposition of technology to facilitate overcoming a conflict. Attention has been given to technology for helping solve conflicts by addressing the basic needs of the two sides, in this way supporting decision-makers. Yet, there is a fundamental question concerned with laypeople involved in a conflict, a question of recognizing the other and shifting attitudes. Intelligent experimental systems have been designed to facilitate the joint creation of a narrative acceptable by participants to the conflict, and studies have been conducted showing that the experience with such systems can help change the attitude toward the other (Zancanaro et al. 2012).

A final note is about ethics in interfaces. In most situations I have tried to describe, the key goal is to motivate individuals and have them find pleasure and interest in going deeper into cultural heritage. Even more obvious is the case of group activity, including the last described goal of nudging participants to the shared narrative. The question of which subtle means for influencing and for nudging through the interface are ethically acceptable must be posed for interfaces and communication. Ethical studies on acceptability of machine persuasive communication (Stock et al. 2016), possibly taking into account different cultures, are an important research theme to be pursued.

In conclusion, I think that we have an extraordinary opportunity with the affirmation of intelligent user interfaces for cultural heritage appreciation. They require 
fundamental interdisciplinarity: they are based on AI and engineering, but give a central role to cognition, to emotion, and to studies about aesthetics and social sciences. In addition, of course, to all the wealth of contents concerned with culture itself.

At the time of the original fourteenth-century humanism, of course the view of culture was just for a small elite. Many centuries later, intelligent digital technology can offer previously unthinkable means for greater appreciation of culture and also extraordinary flexibility: it can help everyone, from the cultural expert to the newcomer, call out his/her inner, human attitude toward learning, toward beauty, and in general toward knowing our (and others') past, potentially thus facilitating the understanding of all that is human. This opportunity is not for the elite; it is for all, in the spirit of the modern meaning of the word humanism. Original humanism was the initial step that led to what came to be known as Renaissance. Will the opportunity of digital humanism be well understood and lead us to a digital Renaissance?

\section{References}

Aliprantis, J. and Caridakis, G. (2019). 'A Survey of Augmented Reality Applications in Cultural Heritage'. International Journal of Computational Methods in Heritage Science. 3, pp. 118-147.

Ardissono, L., Kuflik, T., and Petrelli, D. (2012) 'Personalization in cultural heritage: the road travelled and the one ahead' User Model. User Adapt. Interact. 22(1), pp. 73-99.

Artstein, R., Traum, D., Alexander, O., Leuski, A., Jones, A., Georgila, K., Debevec, P., Swartout, W. and Maio, H. (2014) 'Time-offset interaction with a holocaust survivor' Proceedings of IUI-14, 19th International Conference on on Intelligent User Interfaces, Haifa.

Callaway, C., Stock, O., Dekoven, E. Noy, K., Citron, Y. and Dobrin, Y. (2012) 'Drama and Narrative Variation as a Means to Induce Group Conversation at the Museum' New Review of Hypermedia and Multimedia 18(1-2), pp. 37-61.

Kuflik, T., Stock, O., Zancanaro, M., Gorfinkel, A., Jbara, S., Kats, S., Sheidin, J. and Kashtan, N. (2011) 'A Visitor's Guide in an "Active Museum": Presentations, Communications, and Reflection' Journal on Computing and Cultural Heritage of the ACM, 3(3).

Kuflik, T., Wecker, A., Lanir, J. and Stock, O. (2015) 'An Integrative Framework for Extending the Boundaries of the Museum Visit Experience: Linking the Pre, During and Post Visit Phases' Journal of Information Technology and Tourism 15(1), pp. 17-47.

Stock, O., Guerini, M. and Pianesi, F. (2016) 'Ethical dilemmas for adaptive persuasion systems' Proceedings of AAAI-2016, Phoenix.

Stock, O., Zancanaro, M., Busetta, P., Callaway, C., Krüger, A., Kruppa, M., Kuflik, T., Not, E. and Rocchi, C. (2007) 'Adaptive, Intelligent Presentation of Information for the Museum Visitor in PEACH' User Modelling and User-Adapted Interaction, 17(3), pp. 257-304.

Van Camp, M. and Van den Bosch, A. (2012). 'The socialist network' Decision Support Systems. 53, pp. 761-769.

Zancanaro, M., Stock, O., Eisikovits, Z., Koren, C. and Weiss, P. L. (2012) 'Co-narrating a conflict: An interactive tabletop to facilitate attitudinal shifts' Transactions on Computer-Human Interaction (TOCHI) of the Association for Computational Machinery, 19(3), pp. 1-30. 
Open Access This chapter is licensed under the terms of the Creative Commons Attribution 4.0 International License (http://creativecommons.org/licenses/by/4.0/), which permits use, sharing, adaptation, distribution and reproduction in any medium or format, as long as you give appropriate credit to the original author(s) and the source, provide a link to the Creative Commons license and indicate if changes were made.

The images or other third party material in this chapter are included in the chapter's Creative Commons license, unless indicated otherwise in a credit line to the material. If material is not included in the chapter's Creative Commons license and your intended use is not permitted by statutory regulation or exceeds the permitted use, you will need to obtain permission directly from the copyright holder. 